\title{
What does GRI-Reporting tell us about Corporate Sustainability?
}

\author{
Raine Isaksson \\ Gotland University \\ raine.isaksson@hgo.se \\ Ulrich Steimle \\ Institute of Technology and Work \\ University of Kaiserslauten \\ ulrich.steimle@ita-kl.de
}

\section{Abstract}

\section{Originality/value}

We critically analyze the most common framework for sustainability reporting on an empirical basis. Our qualitative study delivers insights into sustainability reporting in an industry with large impacts on global climate change and living conditions.

\section{Purpose}

We discuss what the business contribution to sustainable development is (or should be) and propose criteria for assessing corporate sustainability. These criteria are applied for the analysis of GRI-reports of five major cement manufacturers. This will result in a discussion if GRI-based sustainability reports really contain the information needed for judging corporate sustainability.

\section{Methodology/approach}

Starting from a literature review of common definitions and principals we develop main criteria of corporate sustainability and propose a set of evaluation criteria for analyzing sustainability reports. We consider definitions and principals from concepts such as Ecoefficiency, Triple-Bottom-Line, The Natural Step and stakeholder value.

Using these criteria we analyze the GRI-based sustainability reports of five major cement manufacturers in order to find out to what extent the reports really address the sustainability performance of the companies.

We chose the companies because of their dominant position in the building material supply chain. The building industry has multiple impacts on the environment as well as on the social system. The decisions and actions of the cement manufacturers have influence on the entire supply chain, from raw material suppliers to the end customer.

\section{Findings}

Our findings lead to the conclusion that the current GRI guidelines are not sufficient to make sustainability reporting for the cement industry relevant and clear. In other words, the guidelines are not sufficient for assuring that a report answers the questions of how sustainable a company is and how quickly it is approaching sustainability. Within the GRI guidelines the needs of the customers are not considered sufficiently. This points at an important area where business excellence ideas can support sustainability reporting. This could be done, for instance, by including the concept of cost of poor quality into sustainability reporting guidelines. 


\section{Keywords}

Sustainability reporting, Stakeholder value, GRI, Business Excellence, Cost of Poor Quality, Process Model.

\section{Category: Research Paper}

\section{Introduction}

Sustainable development and Corporate Social Responsibility (CSR) have become part of the ordinary business and there is today an expectation from customers and other stakeholders that companies report how they work with sustainability. In spite of a broad acceptance that we need to work for sustainability there is still debate on how to best define and describe sustainable development. There is a will to do something but not always a clear idea of what. Companies are scrutinized by customers, shareholders, academia and journalists and it is therefore important to find an acceptable strategy for reporting. An important part of any of these strategies is transparency with the specific requirement of publishing a sustainability report. One of the approaches for reporting with growing popularity is the Global Reporting Initiative guidelines. Companies are seemingly spending time and money on the work with a resulting report coming out in 40-100 pages. What should a reader expect from such a report? Simple questions that beg for on answer are how sustainable a company is and how it is working with sustainable development that will lead to a level of sustainability. These are simple but hard to answer questions since they require that a definition has been formulated on what sustainable development means for the organisation. Our questions are if sustainability reports based on to the GRI-guidelines contain the elements needed for describing corporate sustainability / sustainable development and if they give the required answers to the readers.

\section{Approach}

We have set out to find common recommendations of how to measure sustainable development and sustainability in order to create a list of requirements that we would expect to find in a sustainability report. We have considered and critically reviewed the TripleBottom-Line, Eco-efficiency launched by the World Business Council for Sustainable Development (WBCSD), Global Compact and The Natural Step. We have also looked at the main definition for sustainable development. Additionally we have studied synergies between Total Quality Management and sustainable development and particularly focused on stakeholder theory and on the Cost of Poor Quality as part of sustainability (Isaksson, 2005, 2006). We propose criteria with focus on the measurement of sustainable development. We have limited our study to companies within cement manufacturing. The reason for this is that the main global producers are GRI-reporters and furthermore cement plants have import global effects within all the three dimensions of the Triple Bottom Line. Additionally we have some insight in cement manufacturing which enables us to view the reporting critically. We study the most recent sustainability reports of five major cement companies using our proposed list of criteria.

\section{Definitions for sustainable development and sustainability}

The Brundtland Report definition is well quoted and forms a good starting point: "Sustainable Development is development that meets the needs of the present generation, without compromising the ability of future generations to meet their own needs" (WCED, 1987). This can be interpreted as an acknowledgment to future generations as stakeholders. Economic development is needed to solve the great problems that still plague humanity but it should not destroy the resources needed for the coming generations. Already in a report from the 1970s Limits to Growth, a point was made that humankind was facing problems. The report 
examined five factors that limit global growth. These were population, agricultural production, national resources, industrial production and pollution (Meadows et al., 1972). What is sustainable is a function of the viewpoint, which could go from anthropocentric to ecocentric, putting either humans or nature in focus. Even from an anthropocentric view there is a value in nature because of its multiple functions for humans (production, regulations, carrier, information functions (de Groot, 1992).

The definition in the Brundtland Report is rather general. It allows a wide range of different interpretations. Global operative processes could be described as: "Providing a good life for everybody" and "Safeguarding a healthy nature" (Isaksson and Garvare, 2003). This could be seen as an interpretation of the Brundtland Report with the identification of two main stakeholders - humanity and nature. A stakeholder can be defined as: "Any identifiable group or individual who can affect the achievement of an organization's objectives or who is affected by the achievement of an organization's objectives" (Freeman \& Reed, 1983). In a broad definition the natural environment (animals, plants, natural resources etc.) is also a stakeholder (Starik, 1995). Due to the fact that nature is an indispensable prerequisite for human life and because of the innumerable resource relationships between the nature and economy some authors argue that nature should be considered as the primordial stakeholder of business. (Driscoll \& Starik, 2004; Stead \& Stead, 2000; Starik, 1995). The purpose of this discussion is to put sustainable development in a perspective that relates it to global system origins. A focus on humanity and nature points out the role of corporations as means and supports for sustainability, not as the focal point. This means that even if corporate success is a condition for generating value this should not be on the expense of the core stakeholders.

Sustainable development is not only an issue for nations but also for companies. The reason is that without big corporation's participation it will be hard for nations to drive sustainable development. Already in the Rio-Documents the important role of a business contribution for sustainable development was emphasized. Since humans as customers, shareholders, citizens, politicians and managers start to have a good understanding of what is important there is considerable normative pressure on companies and Corporate Social Responsibility (CSR) increasingly becomes a necessity for success. Today many corporations understand that enduring success depends on various stakeholder groups and on the resources they deliver. That does not concern only tangible resources but also intangibles such as employee qualification, information, network access or legitimacy. For a corporation's survival legitimacy of its activities and outcomes is critical because it is considered the social "license to operate" on which every business depends. The challenge for companies is to be able to show how they work with sustainability, not only by reducing pollution, but also in other more complex ways. CSR is a company's commitment to behave socially and environmentally responsible while striving for its economic goals. CSR includes the company's relations with all its stakeholders, from market-related stakeholders (customers, shareowners, suppliers), to internal (e.g. employees, board of directors) or societal stakeholders (e.g. government, NGOs). It is assumed that the variety of the stakeholders and their concerns lead to corporate responsibility including economical, environmental and social aspects. (Zink \& Steimle, 2008).

The definition of CSR used by the European Commission reflects a concept "whereby companies integrate social and environmental concerns in their business operations and in their interaction with their stakeholders on a voluntary basis." (European Commission, 2001, 8) In this sense, to act socially responsible means not only abiding by the legal regulations, but also going beyond compliance and investing more into human capital, the environment and the relations with stakeholders. Several CSR initiatives emerged during the last years. 
One of the most noted initiatives is the United Nations Global Compact. This network gives a possibility to corporations to show that they, like nations, respect fundamental international standards, such as the Universal Declaration of Human Rights, the International Labor Organization's Declaration on Fundamental Principles and Rights at Work and the Rio Declaration on Environment and Development. It is a network bringing together companies with UN agencies, labor and civil society organizations in order to advance responsible corporate behavior as a business contribution to the challenge of sustainable development in a globalizing economy. The network supports companies in realizing CSR, but also serves as a platform to publicize company's progresses in social and environmental issues. (Leipziger, 2003) If a company wants to become a member of the Compact is has to commit itself to ten principles, which refer to human rights, labor standards, environment and anti-corruption. But if the members of the Compact actually comply with these principles is not being verified.

The growing popularity of initiatives such as the Global Compact or the WBCSD cannot hide the fact that there is still no consensus about defined objectives and measures for sustainable development. But this includes opportunities as well as risks. The broad interpretation range enables a consensus for the different state governments with their partly incompatible interests and also promotes the acceptance of the vision of sustainable development in society and business. On the other side, the lack of binding goals and directives allows rhetorical commitments to sustainability without consequences in behaviour.

The Brundtland Report and the Rio-Documents emphasized interdependencies and interrelations between economic, environmental and social developments. Today the equal weight of these three dimensions is broadly accepted and characteristic for most academic sustainability concepts. Referring to systems theory it is assumed, that if mismanaged (e.g. exceeding specific tolerances) the ecological as well as the social and economic system may loose their ability for self-regulation and break down. Consequently, as a result of positive (i.e. de-stabilizing) feedback mechanisms the other systems will also break down. Besides these interdependencies there often are conflicting goals and trade-off problems between the three dimensions. They have to be balanced in a difficult coordination process in order to refer to development as "sustainable".

Lately global heating has been mentioned as one of the main challenges for humanity and nature. The interpretation of what is sustainable is becoming even harder. One way of trying to relate the different threats is to go back to the main stakeholders, humanity and nature. In the relation diagram in Figure 1 we have related different important problems including the five factors from the Limits to Growth report (Meadows et al., 1972). 


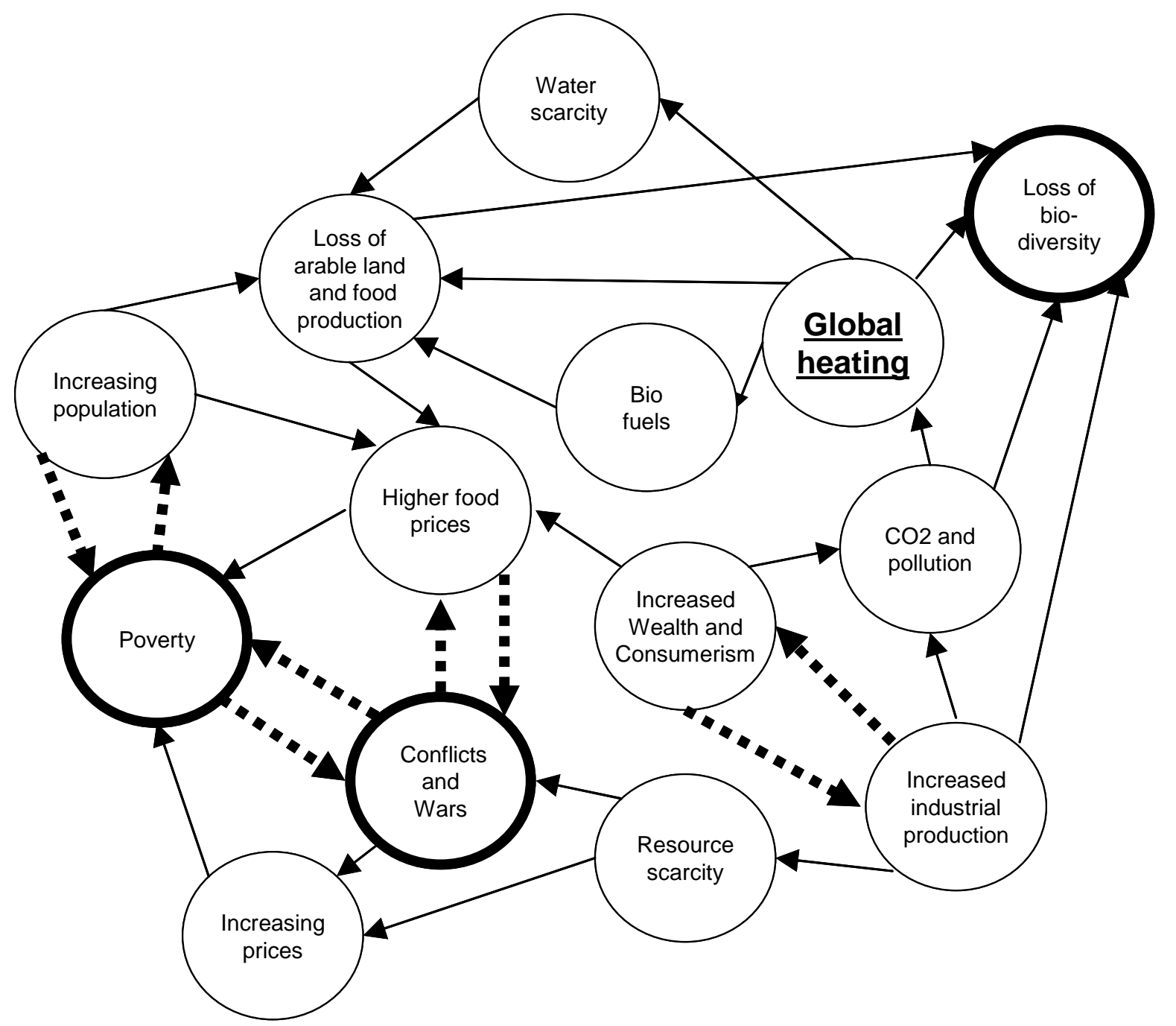

Figure 1 Proposed relation diagram that identifies how the main stakeholders humanity and nature are affected by important global factors. The dotted arrows indicate important reinforcing loops.

The intention is to present approximate relations based on commonly known facts (see e.g. Brown et al., 2007). There are probably important things missing and some of the relations could be disputed but still the relations show how humanity and nature could be affected by different activities. For any corporation it is important to retain the big picture view when describing their role in sustainable development.

The WBCSD coined the expression Eco-efficiency as: "Eco-efficiency is achieved by the delivery of competitively-priced goods and services that satisfy human needs and bring quality of life, while progressively reducing ecological impacts and resource intensity throughout the life-cycle to a level at least in line with the earths estimated carrying capacity. In short, it is concerned with creating more value with less impact” (WBCSD, 2000). This is a way of showing responsibility by linking value to harm. The Triple Bottom Line that describes performance in the economic, environmental and social dimensions has become an accepted way of reporting. This is referred to by the WBCSD and the SAM sustainability index (SAM, 2008).. The problem here is relating the different dimensions. SAM has created a score for each dimension that adds up to one index. The Eco-efficiency proposes the idea of a ratio. In order to live up to the Brundtland Report definition we need to decouple economic growth from pollution (Geiss et al., 2003). Here value is seen as the value created for 
companies and ultimately shareholders. Taking the carbon dioxide emissions as an example, the $\mathrm{CO}_{2}$-productivity used as a term for companies represents this value per harm idea. On a national level, performance can be expressed in $\mathrm{GNP} / \mathrm{t} \mathrm{CO}_{2}$ eq. For Sweden this figure is about 4000 Euro/t $\mathrm{CO}_{2}$. The world average is roughly $1000 \mathrm{EURO} / \mathrm{CO}_{2}$ based on estimated 2008 year figures (Word Gross Product at 40 trillion Euros and world total $\mathrm{CO}_{2}$-eq. emissions at 40 billion tonnes). While weak eco-efficiency only refers to a better value per harm ratio, strong eco-efficiency additionally requires an absolute reduction of environmental harm (von Hauff, Kleine, Jörg, 2005). This means that value per harm could be useful way of comparing processes but not enough to guarantee sustainability.

The Natural Step (TNS) defines four principles for sustainability which are expressed as follows:

"In order for society to be sustainable, nature's functions and diversity are not systematically subject to:

I. increasing concentrations of substances extracted from the Earth’s crust;

II. increasing concentrations of substances produced by society;

III. physical impoverishment by over-harvesting or other forms of ecosystem manipulation; and

IV. resources are used fairly and efficiently in order to meet basic human needs worldwide”. (Robert, 2000)

All these conditions are required for sustainability. If we use this definition, which can be scientifically supported, the conclusion is that a large part of human activity is not sustainable. In order to have a practical relevance the TNS theory uses backcasting, which creates a vision of a sustainable system (Robért, 2000). This vision is then compared with the current situation and the information is used to create a road map towards sustainability. For this roadmap it should be possible to use value per harm indicators.

\section{Sustainability exemplified with global heating}

We could apply backcasting to find out what targets we should set for the indicator value produced per $\mathrm{CO}_{2}$. There is currently a broad understanding based on the work of the IPCC that we should avoid a global temperature increase beyond $2{ }^{\circ} \mathrm{C}$, where the risk increases of passing a tipping point that can lead to uncontrolled heating of the Earth. In order to do this we might have to reduce global $\mathrm{CO}_{2}$-equivalent emissions with $70 \%$ until 2050 from 2008 year levels. Even if this particular target is debatable we use it as an example to show how global system requirements could be factored into sustainability reporting. To reduce emissions we could proceed with two extremes. The first is focusing on reductions of $\mathrm{CO}_{2}$ without considering the effects on economic activity. Since we also need to see that development "meets the needs of the present generation" this would mean some kind of sharing of resources. If we assume the current ratio of 1000 Euro/t $\mathrm{CO}_{2}$ at an average of $6 \mathrm{t}$ $\mathrm{CO}_{2}$ per person and year and the target level of emissions down to less than $2 \mathrm{t} \mathrm{CO}_{2}$ per person and year we can conclude that we should in this case survive at an average of less than 300 Euro per year. This might seem silly but could be the ultimate result of focus on only reducing emissions exemplified with the often heard demand to stop flying to tourist destinations and to stop importing agricultural goods from distant Third World countries. The dominating proposal is to decouple the value creating from $\mathrm{CO}_{2}$-emissions and to have sustainable growth. McKinsey comments that $\mathrm{CO}_{2}$ productivity should increase about 5-7\% 
per year instead of the current 1\%. A 7\% increase per year until 2050 results in an increase of about 17 times. This means that we need to produce about $17000 \mathrm{Euro} / \mathrm{CO}_{2}$. Isaksson et al. (2008) discuss the difficulties with operationalisation of sustainable development and sustainability. (Newton, 2003) labels True Sustainability (TS) of organizations as: "when a social structure can be maintained profitably and indefinitely, without degrading the systems on which it depends". True Sustainable Development is defined as the rate required from the current level to the target level within the time span available (Isaksson et al., 2008). For the indicator of Euro/t $\mathrm{CO}_{2}$ we need an average rate of improvement of $7 \%$. For some branches like cement manufacturing with a currently low $\mathrm{CO}_{2}$-productivity of about 100 Euro/tonne $\mathrm{CO}_{2}$ the increase would have to be $20 \%$ per year over 40 years. For any company or organisation it should be of importance to assess the CO2-productivity and future requirements on it.

We argue that this view of carbon productivity and reference to global limits includes both the TNS backcasting and the Eco-efficiency. Hence, we conclude that one important test of sustainability and sustainable development is to compare with the expected position (True Sustainability) and the rate of approaching it (True Sustainable Development. For the Ecoefficiency variable of Euro/t $\mathrm{CO}_{2}$.

\section{Measuring and assessing performance}

We could apply the Eco-efficiency "value per harm" in a broader sense and state that focus should be on maximising the value produced for all stakeholders compared to the harm done to all stakeholders over the life time of the system. An additional condition is that there are maximal levels of harm for all of the stakeholders. For example, the concept of „Critical Loads“, „Critical Levels“ and „Critical Structural Changes“ represents maximum levels of harm for nature. (SRU, 1994)

Customer focus adds an aspect to the economic dimension of sustainability by focusing on customer value and on the losses of customer value in the form of Costs for Poor Quality (Campanella, 1999). Cost of Poor Quality (CPQ) has been defined by Joseph Juran: The costs of poor quality are zero when processes and products are perfect. A company with a high CPQ could still be profitable by passing the costs to the customer by overcharging, (Isaksson, 2005). This indicates that the sales value produced is a necessary but not a sufficient indicator for economic sustainability. In a perfect market the company producing the best perceived customer value gets the business. We therefore argue that customer value can serve as an indicator for the economic dimension of the Triple Bottom Line with the benchmark being a perfect product from a perfect process. Using the principle from Eco-efficiency we can relate this value to harm. To simplify and exemplify we can choose the main environmental harm for a company. For many industries this could be the $\mathrm{CO}_{2}$-emissions. In order to address the social dimension we claim that in the case of basic products sold in poor countries price is an important indicator for social harm. It can be shown that poor often pay more than rich for basic goods, (Prahalad, 2006). Prahalad argues that there is money to be made at the bottom of the pyramid, but that is also could be seen as doing social good. The important issue for poor and rich, however, is the value for price ratio. The TBL for cement industry could therefore, based on (Isaksson, 2007) be simplified to:

- Economic performance: Customer value

- Environmental performance: Customer value/environmental harm

- Social performance: Customer value/price 
Comparing customer value to price is common in different types of consumer magazines that rate different products. Another argument for using value/price as a social indicator and as part of the TBL is that paying less for commodities liberates money for other purchases that can improve well-being. When more customer value is produced for the same product unit this leads at the same level of customer consumption to reduced production and thereby reduced emissions.

We believe that when possible the KPI customer value per environmental harm and price as social harm should be included when sustainability and sustainable development are assessed. Establishing benchmarks could be challenging in some cases, but should not be impossible.

\section{Assessing sustainability reporting}

Various recommendations and guidelines for sustainability reporting have been published during the last years. Most prominent and most widely used are the Global Reporting Initiative (GRI) Guidelines. GRI was founded in 1997 by the Coalition for Environmentally Responsible Economies (CERES) and the United Nations Environmental Programme (UNEP). The GRI Guidelines were initially published in 2000. Their purpose is to support companies in creating sustainability reports that integrate social, environmental and economic impacts of business. The GRI intends to establish their guidelines as an internationally accepted framework that promotes comparable sustainability reporting. The current version of the guidelines (GRI-G3) was published in 2006. The new framework contains principles and guidance for defining content and quality of the sustainability report as well as for setting the report boundaries, i.e. the decision, which entities of the company are included in the report. The guidelines require standard contents for sustainability reporting regarding the organization's profile, its governance-structures and processes, and the management of sustainability issues including goals and environmental, social and economic performance indicators. In the context of a comprehensive CSR approach it can be seen as strength that GRI guidelines are compatible with the principles of the United Nation Global Compact.

To give an answer to the research question "What does GRI-Reporting tell about Corporate Sustainability?” we decided to assess the GRI-structured Sustainability Reports of five major building material manufacturers. Our aim was to find out to what extent the reports really address the sustainability performance of the companies. We chose the companies because of their dominant position in the building material supply chain. The decisions and actions of the building material manufacturers influence the entire building supply chain, from raw material suppliers to the end customer of the completed building. The building industry has multiple impacts on all the Triple Bottom Line dimensions globally.

We chose an approach in some aspects similar to the Structuring Content Analysis as described by (Mayring, 1990). This technique aims to extract specific aspects from the entire text material and to estimate the contents under certain criteria. For extracting relevant contents from the sustainability reports we created four criteria based on our theoretical assumptions. Then we identified sections and paragraphs in the reports, which include contents related to these criteria and made a compilation of relevant material for each company.

The simple question of an interested reader looking at a sustainability report is how sustainable is the company and how are they improving. In order to assess this, what is presented should be relevant. See figure 2 for a proposal. 


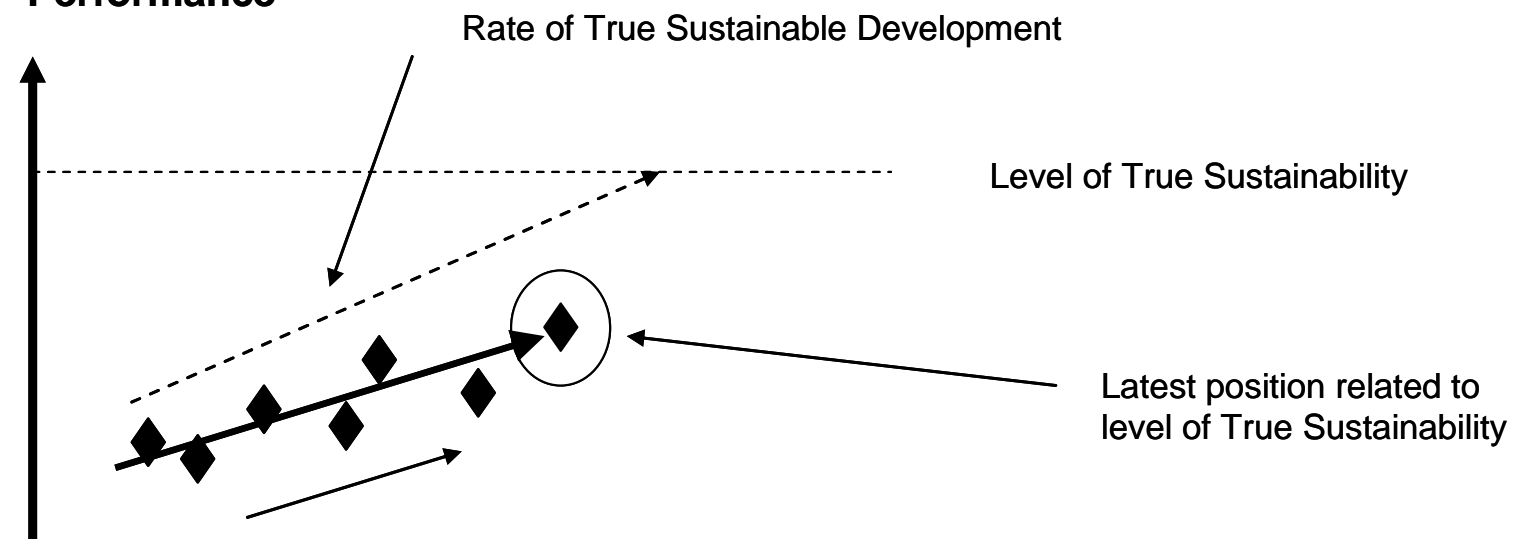

Rate of improvement that can be compared to True Sustainable Development

\section{Time}

Figure 2 Performance in function of time that describes level of sustainability and progress towards sustainability for relevant indicators.

This would mean that the company has identified its main sustainability aspects and created relevant indicators for monitoring the position and development. We will therefore focus our assessment on results presented in relation to what would be expected when looking at the main stakeholders and main sustainability aspects. Based on our previous discussions we focus on how sustainability reports address effects on global warming and on poverty because we consider those as the main sustainability issues. This puts focus on the stakeholders customer and nature.

We base our assessment on four main criteria:

1. Relevance of chosen KPIs: Which indicators are reported that refer to customer value, environmental harm and social harm?

2. Clarity of level - How well are the main indicators describing the relative level of sustainability compared to other companies in the same industry?

3. Clarity of improvement - How well are main indicators describing progress? Are trends reported and are the trends benchmarked?

4. System view - Have benchmarks been defined in such a way that it is possible to relate indicators to objective sustainability requirements (True Sustainability and True Sustainable Development)

\section{Assessing the cement industry}

Before carrying out the assessment of the sustainability reports we convert our general assessment to a specific one for the cement industry.

The global cement industry is currently responsible for $5 \%$ of the man made carbon emissions, (WBCSD, 2002). The industry is growing with a rate of some $4 \%$ per year, mainly in the developing countries. Cement manufacturing forms an important part in the building material supply chain. Buildings are currently consuming some $40 \%$ of the world's energy requirements and the effect on $\mathrm{CO}_{2}$-emissions from the building sector is considerable, (WBCSD, 2007). For housing we could find a benchmark level of space needed and benchmark energy consumption for the lifespan of a building in for example person $\mathrm{m}^{2}$ living space per year/t $\mathrm{CO}_{2}$. It is generally acknowledged that the main environmental challenge in 
the cement industry consists of reducing $\mathrm{CO}_{2}$-emissions. For large urban centres in Third World countries concrete is often the main building material which cannot easily be substituted. Hence, the environmental challenge is to maximise building value for minimised $\mathrm{CO}_{2}$-emissions. Our value per environmental harm indicator becomes building value per $\mathrm{CO}_{2}$ emissions. Since building needs are high in poor countries we argue that cement price is an important social indicator. The best contribution from the industry for alleviating poverty is by providing maximal building value for minimal price. This means that reporting in order to be relevant should contain information of the value produced for customers and the harm done in form of $\mathrm{CO} 2$-emissions and prices paid by customers. The main driver of CO2emissions is the fuel consumed for clinker burning and therefore the specific energy consumption for this is of interest.

\section{Findings}

All the companies in our study follow the Cement Sustainability Initiative of the WBCSD recommendations that also recommend the use of the GRI reporting guidelines. To indicate that a report is GRI-based the companies are expected to self-declare the so-called Application Level (C, B or A) that describes to which extent the report covers the GRI Reporting Framework. The A level requires the most comprehensive coverage of the GRI criteria. Additionally, the reporting companies can obtain a third party opinion on the accuracy of the self-declared Application Level or let the Global Reporting Initiative check the self-declaration.

If external assurance was applied for the report, the Application Levels of $\mathrm{C}+, \mathrm{B}+$ or $\mathrm{A}+\mathrm{can}$ be declared to indicate that the report was evaluated by a qualified and independent organisation. In this case a statement of the assurance provider has to be added to the report.

One company in our study does not declare an Application Level, but states that GRI guidelines were used as a basis for the report (Heidelberg Cement 2007). The other sustainability reports are self-declared Application Level B (Lafarge 2007), GRI checked Level B (CEMEX 2006), third party checked Level A+ (TITAN 2007), and GRI checked Application Level A+ (Holcim 2007). We therefore conclude that the reports can be used for empirically assessing GRI-based sustainability reporting.

\section{Relevance of chosen KPIs}

While climate change is one of the main issues in all the reports, poverty issues are weighted differently. In our analysis the question is how value for customer is presented and how well the value produced is compared to harm done. Our findings from the analysis of the sustainability reports can be summarized as follows:

- Value produced is given in total tonnes of cement sold and/or in the sales value and its distribution. There is no quantitative assessment of customer value but in some reports customer focus and its importance as well as customer satisfaction measurements are mentioned. Several qualitative statements related to value per harm can be found such as "We are as much concerned about minimizing these impacts as we are about maximizing the benefits."

- Carbon emissions are reported as total and specifically as $\mathrm{kg} \mathrm{CO}_{2} /$ tonne cement by all companies and in some reports indirectly as percentage of clinker per tonne of cement. These are the indicators closest to the idea of value per harm.

- Specific energy consumption per tonne of clinker is only reported by some companies.

- Social indicators focus on human resources (e.g. training, occupational health and safety), community and doing charity. Poverty is sometimes mentioned as an important issue and there are single initiatives (e.g. cement donations for social projects or special credit 
systems for low income customers in single regions), but no quantitative indicators are reported regarding market prices.

\section{Clarity of position}

We found no comparisons of environmental main indicators (absolute and specific $\mathrm{CO}_{2}$ emissions and specific energy consumption for clinker) with results of other companies or with industry average. None of the reports contains comparisons of social indicators other than accident or fatality rates.

\section{Clarity of change}

The majority of the companies present trends for three or more years for the environmental main indicators.. Comparisons of progress with other companies or with industry average cannot be found in the analyzed reports.

\section{System view}

All the cement manufacturers in our study set targets to reduce $\mathrm{CO}_{2}$-emissions per tonne with a certain percentage in a defined time period (e.g. 20\% reduction from 1990 to 2010). However, these targets are in no case related to external requirements of True Sustainable Development. Technical limits for specific energy consumption and for clinker substitution are not taken up. There is no explicit discussion on carbon productivity and the challenge the industry has in improving its carbon productivity.

\section{Other findings}

Looking at the sustainability reports from a TQM or excellence perspective some areas for improvement become obvious. First of all, in the reports there is no clear differentiation of enablers and results. This is could originate from the fact that the GRI guidelines lack both customer focus and process orientation. Resource indicators and result indicators are not differentiated, but all considered to be bottom-line indicators. Lafarge discusses the importance of looking at the entire life cycle of buildings and points out that construction material only corresponds to $12 \%$ of the energy use when studied over a 50 year lifespan for a building. This could be one way of considerably improving the carbon productivity by focusing on the end product of living space instead of on cement only. Cemex has an initiative called "Patrimonio Hoy" where low income families are receiving help with financing house extensions and house building. Some companies report on their environmental management systems and one even indicates that a Sustainability Management System that will be mandatory for all business units is being implemented at the moment.

\section{Conclusions and discussion}

The conclusions from our findings are that performance indicators in the reports are only partly relevant. Information on the main environmental harm of $\mathrm{CO}_{2}$-emissions is well presented and it is partly related to performance when given as a ratio of emissions per tonne of cement. However the value of the tonne of cement is not clearly expressed since cement comes in different strength classes. Based on the European Standard there are three classes of cement which have minimum performance for the compressive strength at 28 days rated as 32,5, 42,5 and 52,5 Mega Pascal (MPa) (EN 197-1, 2000). Internationally there are standards with even lower strengths, which means that cement performance could range from 30 to 60 $\mathrm{MPa}$ as the 28 day value. Since building value can be related to cement strength the value for a tonne of cement could vary with a factor of two. Theoretically it would thus be possible for a cement company to reduce the percentage of clinker and the carbon emissions per tonne by lowering the quality. 
All companies elaborate on the use of alternative fuels and plans for increasing the percentage. There is no mention that an increased used of waste fuels normally leads to increased specific energy consumption for clinker burning. Those companies reporting the specific energy consumption show either a stable level or an increase in the specific energy consumption. The reported levels are about $20 \%$ above best possible performance. It could be debated if the substitution rate with alternative fuels really is the environmental indicator that the industry claims it to be. This means that an increase in specific energy consumption due to use of alternative fuels is not acceptable.

The majority of world's population is poor and developing countries are the main market for most global cement companies. Considering this, the conclusion must be that the social reporting has a very low relevance due to lack of customer focus. For the low income customer the most important thing is performance per price. None of the companies reports this.

For the environmental indicators reported most companies report both level and progress, but compare neither level nor progress to industry benchmarks. For the reader it becomes very difficult to know how a particular company compares with another one.

Global requirements on carbon emissions are not translated to company targets. For instance, Lafarge looks at the future and describes a vision of reduced energy use in buildings with $75 \%$. This is however not translated to any improvement requirements for cement production.

Since all companies follow the GRI-G3 guidelines this leads to the conclusion that these are not sufficient to make sustainability reporting for the cement industry relevant and clear. In other words, the guidelines are not sufficient for creating a report that answers the questions of how sustainable a company is and how quickly they are approaching sustainability (if not sustainable).

This analysis of the sustainability reports shows that the needs of the customers are not considered sufficiently within GRI-G3. This highlights an important area where business excellence theory can support sustainability reporting. This could be done, for instance, by including the concept of cost of poor quality into sustainability reporting guidelines.

The main limitation of our research stems from the fact that only one industry was considered. For the cement industry we can show that sustainability reports do not contain all relevant information for judging corporate sustainability even though they are rated A according to the Application Levels of GRI. We suppose that this is also true for other industries, but further empirical research remains to be done.

Furthermore, our results and conclusions regarding the GRI-G3 are strongly determined by the evaluation criteria we used and the underlying definition of corporate sustainability - there are, of course, no "right” or "wrong” definitions of this normative concept.

\section{References}

Brown, O. \& Hammill, A. \& Moleman, R. (2007), "Climate change as the 'new' security threat: implications for Africa”. International Affairs, 83, 6, 1141-1154.

de Groot, R. (1992). Functions of Nature. Evaluation of Nature in Environmental Planning, Management and Decision Making. Wolters-Noordhoff, Groningen.

Campanella, J, (1999). Principles of Quality Costs - Principles Implementation and Use.Third edition. ASQ Quality Press, Milwaukee, Wisconsin. 
Driscoll, C. \& Starik, M. (2004), “The Primordial Stakeholder: Advancing the Conceptual Consideration of Stakeholder Status for the Natural Environment”. Journal of Business Ethics, 49, 1, 55-73.

EN 197-1 (2000). Cement - Part 1: Composition, specifications and conformity criteria for common cements, EN 197-1:2000E, European Committee for Standardization, Brussels.

European Commission (2001), Promoting a European framework for corporate social responsibility - green paper. Office for Official Publications of the European Commission, Luxembourg.

Freeman, R.E. \& Reed, D.L. (1983), "Stockholders and Stakeholders: A New Perspective on Corporate Governance”. California Management Review, 25, 3, 88-106.

Geiss, J.; Wortmann, D.; Zuber, F. (2003), “Nachhaltige Entwicklung - Strategie für das 21. Jahrhundert?“ In: Geiss, J.; Wortmann, D.; Zuber, F. (Eds.), Nachhaltige Entwicklung Strategie für das 21. Jahrhundert? Eine interdisziplinäre Annäherung. Leske und Budrich, Opladen, 17-40.

Hauff, M.v.; Kleine, A. \& Jörg, A. (2005), Förderung der Wettbewerbsfähigkeit in Kleinunternehmen durch Ökoeffizenz. Verlag Wissenschaft und Praxis, Sternenfels.

Isaksson, R. \& Garvare, R. (2003), "Measuring sustainable development using process models“. Managerial Auditing Journal, 18, 8, 649-656.

Isaksson, R. (2005), "Economic sustainability and the Cost of Poor Quality". Corporate Social Responsibility \& Environmental Management, 12, 197-205.

Isaksson, R. (2006), "Total Quality Management for Sustainable Development - process based system models”. Business Process Management Journal, 12, 5, 632-645.

Isaksson (2007), Product quality and sustainability in the cement industry - Proceedings of the $12^{\text {th }}$ International Conference on Cement Chemistry, Montreal, Canada, July 8-13.

Isaksson, R. \& Hallencreutz, J. \& Garvare, R. (2008), Process Management and SystemThinking for Sustainable Development. Chapter xx, pxxx Book under publication. (Ed. K.J. Foley et al.), Consensus Books, Sydney.

Leipziger, D. (2003), The Corporate Sustainability Code Book. Greenleaf, Sheffield.

Mayring, Ph. (1990), Qualitative Inhaltsanalyse. Grundlagen und Techniken. Deutscher Studienverlag, Weinheim.

Meadows, D. H. \& Meadows, D. L. \& Randers, J. \& Behrens III, W. W. (1972), The Limits to Growth - A Report for the Club of Rome's Project on the Predicament of Mankind, Potomac Associates Book, Earth Island Ltd, London.

Newton, L.H. (2003) Ethics and Sustainability - Sustainable Development and the Moral Life, New Jersey, Prentice Hall.

Prahalad, C., K. (2006), “The Fortune at the Bottom of the Pyramid - Eradicating Poverty Through Profits”. Wharton School Publishing.

Robért, K-H. (2000), Tools and concepts for sustainable development, how do they relate to a general framework for sustainable development, and to each other? Journal of Cleaner Production, 8(3), 243-254.

SAM (2008). SAM Yearbook 2008. Retrieved 08-06-14 from http://www.samgroup.com/downloads/YB/Yearbook_2008.pdf 
SRU - The German Advisory Council on the Environment (1994), Environmental Report. In Pursuit of Sustainable Environmentally Sound Development. Metzler-Poeschel, Stuttgart. (Bundestag Publication \#12/6995).

Starik, M. (1995), "Should Trees Have Managerial Standing? Toward Stakeholder Status for Non-Human Nature”. Journal of Business Ethics, 14, 3, 207-216.

Stead, J.G. \& Stead, E. (2000), “Eco-Enterprise Strategy: Striving for Sustainability”. Journal of Business Ethics, 24, 4, 313-329.

Zink, K.J. \& Steimle, U. (2007), “Corporate Social Responsibility and Organizational Excellence Linking Stakeholder Approach and Resource-Based View.” Paper presented at the $6^{\text {th }}$ international MAAOE Conference New Perspectives on the Theories and Practices of Organizational Excellence, University of Versailles Saint-Quentin-EnYvelines, June 19-22, 2007.

WBCSD (2000). Eco-Efficiency, creating more value with less impact. www.wbcsd.org.

WBCSD (2002). The Cement Sustainability Initiative -Our agenda for action. www.wbcsd.org

WBCSD (2007). Energy Efficiency in Buidlings - Business realities and opportunities. www.wbcsd.org

WCED - World Commission on Environment and Development (1987), Our Common Future: Report of the World Commission on Environment and Development. Oxford University Press, Oxford. 